\title{
Biodegradable Polymers: New Alternatives Using Nanocellulose and Agroindustrial Residues
}

Josué Hernández-Varela ${ }^{1}$, José Jorge Chanona-Pérez ${ }^{2}$, Paloma Resendis Hernández ${ }^{1}$, Silvia Villaseñor Altamirano $^{1}$, Hector Calderon ${ }^{1}$, Katia Mundo Franco ${ }^{1}$ and Evans Alvarado Santiago ${ }^{1}$

${ }^{1}$ Instituto Politécnico Nacional, Ciudad de México, Distrito Federal, Mexico, ${ }^{2}$ Escuela Nacional de Ciencias Biológicas. Instituto Politécnico Nacional, Mexico, Distrito Federal, Mexico

Currently, the world faces the consequences of contamination by petroleum-derived plastics (plates, glasses, cutlery) which causes the search for new biodegradable materials based on agro-industrial lignocellulosic residues that help reduce their use and create more friendly waste with the environment [1,2] The use of garlic skin (GS) as a raw material in form of cellulose microfibers (CMF) and also as a precursor to cellulose insulation to obtain microcrystalline cellulose (MCC) to make a composite film that is biodegradable is presented below. To achieve biodegradable films, mixtures of potato starch, gellan gum and glycerol with CMF were used for future use as food utensils (dishes); On the other hand, chitosan (Q), alginate (A) and MCC, were used to obtain a film capable of removing dyes from water and absorbing gases. These CMFs were used in the preparation of biodegradable films for food utensils and cellulose nanoparticles from garlic skin (CNP-GS) were used in the removing dye films. Both materials were easily analyze using scanning electron microscopy (SEM) as a powerful technique to evaluate the surface and cross-sectional views in the materials and understand the arrangement of the polymers.

To obtain cellulose microfibers (CMF), $10 \mathrm{~g}$ of selected and ground samples were stirred with hot water $\left(80{ }^{\circ} \mathrm{C} \mathrm{x} 3 \mathrm{~h}\right)$ and dried in an air oven at $80{ }^{\circ} \mathrm{C}$ for $4 \mathrm{~h}$. Subsequently, an extraction with ethanol/toluene

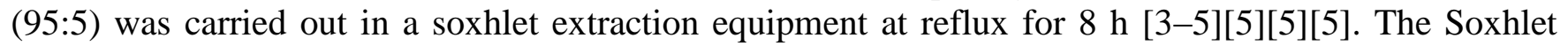
apparatus was used with ethanol/toluene to remove other soluble compounds and not polar compounds [6]. Until here, CMFs were obtained to prepare the films with raw material. In other hand, the MCC isolation was carried out using alkaline extraction with a $\mathrm{NaOH} 5 \%$ solution at $80^{\circ} \mathrm{C}$ by $5 \mathrm{~h} \mathrm{[7].} \mathrm{A}$ bleaching treatment with a 1:1:1 solution of acetate buffer $(\mathrm{pH}=4.5)$, aqueous chlorite $\left(1.7 \mathrm{wt} \%\right.$ in $\left.\mathrm{H}_{2} \mathrm{O}\right)$ and distilled water was used with a pulp/solution ratio of $1: 50$ at $85{ }^{\circ} \mathrm{C}$ by $2 \mathrm{~h}$ [8]. The final MCC was neutralized, dried and milled using a planetary mill (PULVERISETTE 7, Fritsch GmBH, Idar-Oberstein, Germany) in containers ( $45 \mathrm{~mL})$ and agate balls $(5 \mathrm{~mm})$ for $2 \mathrm{~h}$ to obtained the CNP-GS [9].

For the films with raw material (Figure 1a), solutions of $1.5 \% \mathrm{w} / \mathrm{v}$ potato starch and $1 \% \mathrm{w} / \mathrm{v}$ gellan gum were prepared and binary mixtures were made in a 1:1 ratio using 5\% glycerol as a plasticizer. The concentration added of CFM was 2\%, and different sizes of particles (1410, 212 and 38 um) were used. For the films with CNP-GS (Figure $1 \mathrm{~g}$ ), a 1:1 solution of alginate $(1.5 \% \mathrm{w} / \mathrm{v})$ and chitosan $(1 \% \mathrm{w} / \mathrm{v}) \mathrm{in}$ $2 \% \mathrm{v} / \mathrm{v}$ acetic acid was prepared [1]. The final nanoporous membrane (NPM) was made by adding $0.1,0.3$ and $0.5 \%$ of CNP-GS to the alginate/chitosan solution (Fig. 1h) and dried at oven $\left(60^{\circ} \mathrm{C} \times 12 \mathrm{~h}\right)$ and cryostat $\left(-34{ }^{\circ} \mathrm{C} \times 1\right.$ week). The films presented a visual appearance similar to that reported by other authors [1,10] and showed no characteristic odor. Final films in optical (Fig. 1b) and SEM images (Fig. 1d-f) presented promising mechanical characteristics for the preparation of dishes, being the one that contains $2 \%$ of MFC and 38 um of particle size, which shows a greater resistance and elasticity to be subjected to a thermoforming process (6.06 N vs $11.13 \mathrm{~mm})$ (Figure 1c).

On the other hand, the composite with alginate and chitosan (Fig. 1g) and the film reinforced with CNPGS (Fig. 1h) presented a good removal of dyes in a solution of known concentration of methylene blue that it was evaluated using UV-Vis spectroscopy at $664 \mathrm{~nm}$ (Fig. 1i). All membranes showed comparable 
physicochemical characteristics but the membrane with $0.1 \% \mathrm{CNP}$ had a lower solubility. The pH (3.54), solubility $(93.15 \pm 0.18 \%)$ and thickness $(150 \mathrm{um})$ were similar to those reported by other authors [1]. The NPM $0.1 \%$ showed a higher removal percentage $(50.86 \pm 0.43 \%)$ in comparison with other membranes.

For new applications of these NPMs, the congelation and later dried at $-34{ }^{\circ} \mathrm{C}$ of the chitosan/alginate composite was a good alternative to obtain a material similar to expanded polystyrene (EPS) that is used in food tracks and recipients due to their thermal, resistance and harmless properties [11]. Figure 2 displays the SEM and optical pictures of NPM $0.1 \%$, as well as the surface and cross-sectional, vies of alginatechitosan modified with CNP-GS. In the top view (Fig. 2a and 2c) the NPM show a rough surface that is characteristic of the membranes when there are dried in the freezer. The non-uniformity and defect holes are clearly observed, making the porous structure a very define material (Fig. 2c). In the lateral view of SEM images (Fig. 2b and 2d) it's possible to observe a well-defined laminar structure (950.35 \pm 273.20 $\mathrm{nm}$ ), inside of each laminar wave sand-like is characteristic of these structures with CNP. The results clearly indicate that even at this loading level CNPs are still uniformly distributed and dispersed individually with the formation of layered lasagne-like structure (Fig. 2d) [12]. The evaporation of water inside of these structures is slower than in an oven but, permits to obtain different cavities inside of the NPM [12]. The authors suppose that the alginate-chitosan complex facilitates the formation of ionic for both in chitosan (cation) and alginate (anion) matrix structure associated with the presence of ionized functional groups, that was proposed, e.g. by [13]. Figure 2 also shows the composition of the garlic skin used as native material and the isolated cellulose for further milling [14].

The most promising results showed that the mixture of alginate, chitosan and nanocellulose based could be a biodegradable alternative for the removal of dyes thanks to the electrostatic interaction of the NPC with the chemical dye charge. Also, brings the opportunity to evaluate other materials (potato starch, gellan gum, and raw material) more biodegradables for food utensils. 

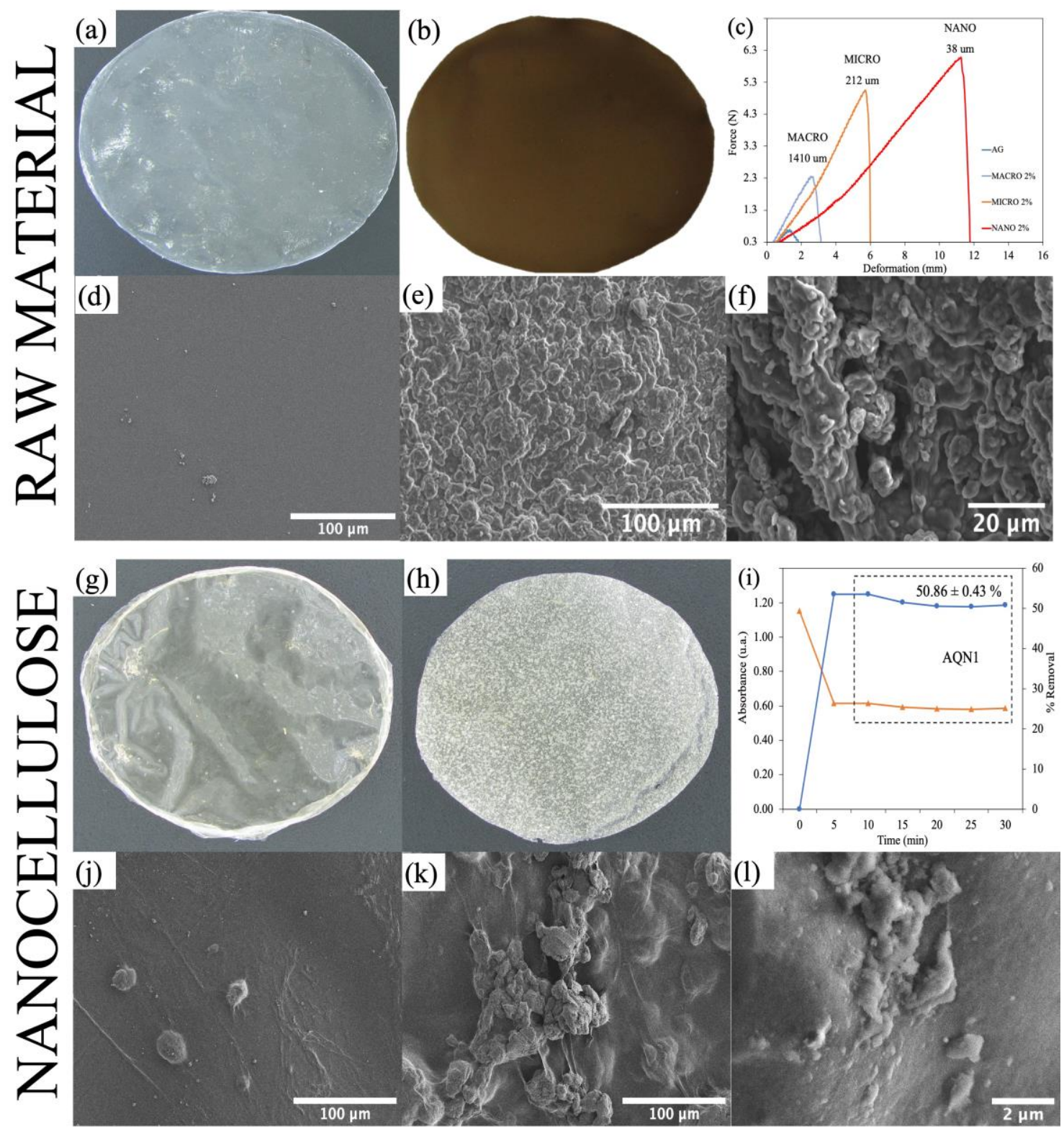

Figure 1. Optical and SEM images of biodegradable films for raw material (a-f) and por nanocellulose (g-l). Fig. 1c show the textural test for these films. Fig. 1i show the removal of methylene blue in solution with the alginate-chitosan composite. 


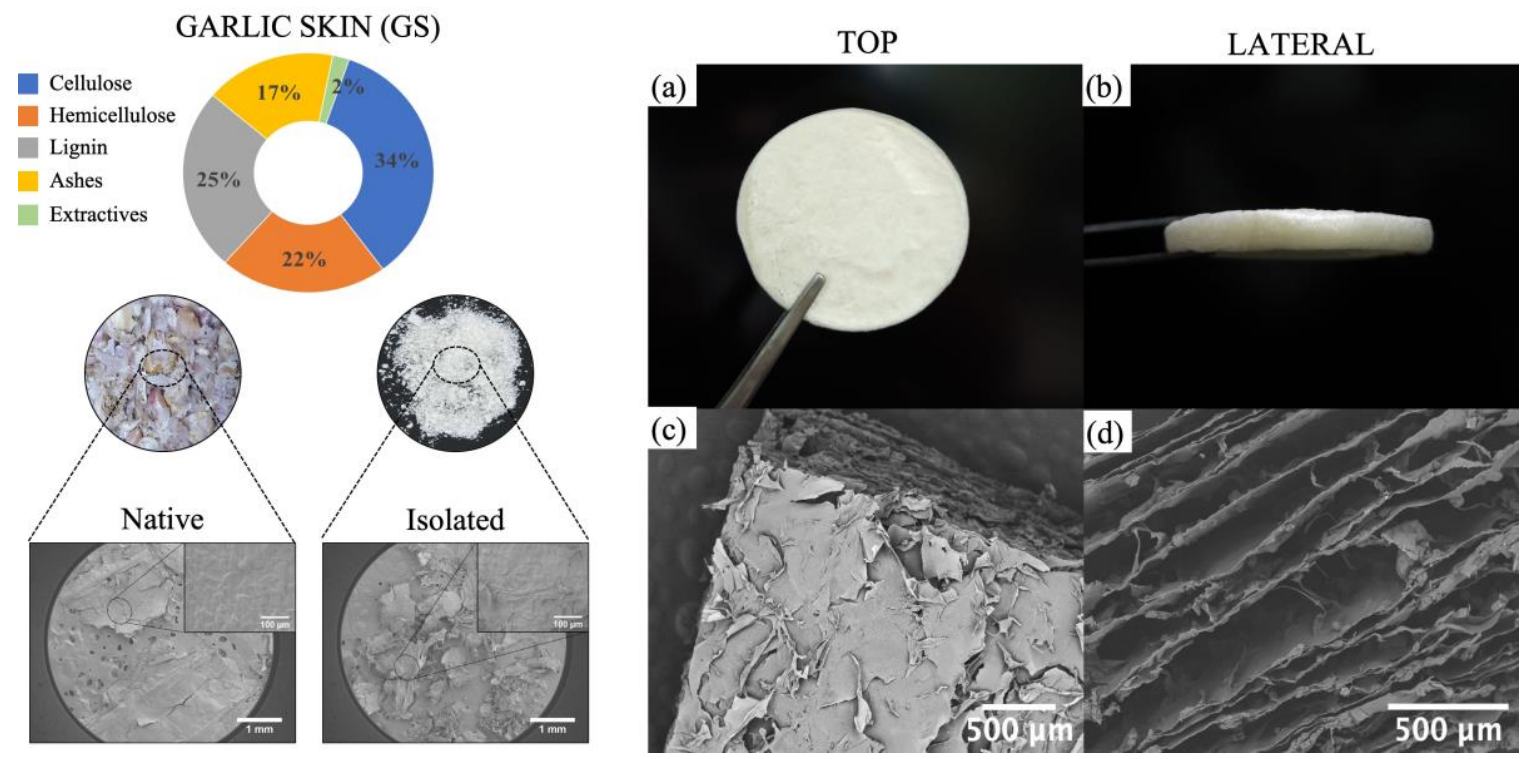

Figure 2. SEM images of biodegradable films for nanocellulose in top (a,c) and lateral view (b,d). Fig. 2 also shows the initial composition of garlic skin used to obtain the raw material and the cellulose isolated.

References

[1] J.S. Alvarado-González, J.J. Chanona-Peréz, J.S. Welti-Chanes, G. Calderón-Domínguez, I. ArzateVázquez, S.U. Pacheco-Alcalá, V. Garibay-Febles, G.F. Gutiérrez-López, Rev. Mex. Ing. Química 11 (2012) 193-210.

[2] E. Espino, M. Cakir, S. Domenek, A.D. Román-Gutiérrez, N. Belgacem, J. Bras, Ind. Crops Prod. 62 (2014) 552-559.

[3] C. Gumeta-Chávez, J.J. Chanona-Pérez, J.A. Mendoza-Pérez, E. Terrés-Rojas, V. Garibay-Febles, G.F. Gutiérrez-López, Dry. Technol. 29 (2011) 612-623.

[4] H.M. Hernández-Hernández, J.J. Chanona-Pérez, G. Calderón-Domínguez, M.J. Perea-Flores, J.A. Mendoza-Pérez, A. Vega, P. Ligero, E. Palacios-González, R.R. Farrera-Rebollo, Microsc. Microanal. 20 (2014) 1436-1446.

[5] M. Szymanska-Chargot, M. Chylinska, K. Gdula, A. Koziol, A. Zdunek, Polymers (Basel). 9 (2017).

[6] H.M. Hernández-Hernández, J.J. Chanona-Pérez, A. Vega, P. Ligero, R.R. Farrera-Rebollo, J.A. Mendoza-Pérez, G. Calderón-Domínguez, N. Güemes, Microsc. Microanal. 22 (2016) 1084-1097.

[7] J. Prasad Reddy, J.W. Rhim, Mater. Lett. 129 (2014) 20-23.

[8] G. Siqueira, K. Oksman, S.K. Tadokoro, A.P. Mathew, Compos. Sci. Technol. 123 (2016) 49-56.

[9] E.E. Neri-Torres, J.J. Chanona-Pérez, H.A. Calderón, N. Torres-Figueredo, G. Chamorro-Cevallos, G. Calderón-Domínguez, H. Velasco-Bedrán, Microsc. Microanal. 22 (2016) 887-901.

[10] M. Escamilla-García, G. Calderón-Domínguez, J.J. Chanona-Pérez, R.R. Farrera-Rebollo, J.A. Andraca-Adame, I. Arzate-Vázquez, J. V. Mendez-Mendez, L.A. Moreno-Ruiz, Int. J. Biol. Macromol. 61 (2013) 196-203.

[11] R. Meftah, J. Van Stappen, S. Berger, G. Jacqus, J. Laluet, P. Guering, L. Hoorebeke, V. Cnudde, Materials (Basel). 12 (2019) 1-13.

[12] G. Dudek, R. Turczyn, (2018) 39567-39578.

[13] S. V Kononova, A. V Volod, V.A. Petrova, E. V Kruchinina, Carbohydr. Polym. 181 (2018) 86-92.

[14] Technical Association of Pulp and Paper Industry, TAPPI test methods (1997) 12. 